Article

\title{
Internal Force on and Deformation of Steel Assembled Supporting Structure of Foundation Pit under Thermal Stress
}

\author{
Fu Wang ${ }^{1,2,3}$, Guijun Shi ${ }^{4,5}$, Wenbo Zhai ${ }^{1,2,3}$, Bin Li ${ }^{1,2,3, *}$, Chao Zhang ${ }^{1,2,3, *(\mathbb{D})}$ and Hongyuan Fang ${ }^{1,2,3,6}$ \\ 1 School of Water Conservancy Engineering, Zhengzhou University, Zhengzhou 450001, China; \\ wf19960601@outlook.com (F.W.); zwb207@outlook.com (W.Z.); fanghongyuan@zzu.edu.cn (H.F.) \\ 2 National Local Joint Engineering Laboratory of Major Infrastructure Testing and Rehabilitation Technology, \\ Zhengzhou 450001, China \\ 3 Collaborative Innovation Center of Water Conservancy and Transportation Infrastructure Safety, \\ Zhengzhou 450001, China \\ 4 CCCC First Highway Consultants Co., Ltd., Xi'an 710065, China; shiguijun2021@outlook.com \\ 5 Xi'an CCCC Environmental Engineering Co., Ltd., Xi'an 710065, China \\ 6 Southern Engineering Inspection and Restoration Technology Research Institute, Huizhou 516029, China \\ * Correspondence: libin19931123@gs.zzu.edu.cn (B.L.); chao.zhang.zzu@outlook.com (C.Z.); \\ Tel.: +86-135-2351-9067 (B.L.)
}

check for updates

Citation: Wang, F.; Shi, G.; Zhai, W.; Li, B.; Zhang, C.; Fang, H. Internal Force on and Deformation of Steel Assembled Supporting Structure of Foundation Pit under Thermal Stress. Appl. Sci. 2021, 11, 2225. https:// doi.org/10.3390/app11052225

Academic Editor: Chiara Bedon

Received: 5 February 2021

Accepted: 1 March 2021

Published: 3 March 2021

Publisher's Note: MDPI stays neutral with regard to jurisdictional claims in published maps and institutional affiliations.

Copyright: (c) 2021 by the authors. Licensee MDPI, Basel, Switzerland. This article is an open access article distributed under the terms and conditions of the Creative Commons Attribution (CC BY) license (https:/ / creativecommons.org/licenses/by/ $4.0 /)$.
Abstract: The steel assembled support structure of a foundation pit can be assembled easily with high strength and recycling value. Steel's performance is significantly affected by the surrounding temperature due to its temperature sensitivity. Here, a full-scale experiment was conducted to study the influence of temperature on the internal force and deformation of supporting structures, and a three-dimensional finite element model was established for comparative analysis. The test results showed that under the temperature effect, the deformation of the central retaining pile was composed of rigid rotation and flexural deformation, while the adjacent pile of central retaining pile only experienced flexural deformation. The stress on the retaining pile crown changed little, while more stress accumulated at the bottom. Compared with the crown beam and waist beam 2 , the stress on waist beam 1 was significantly affected by the temperature and increased by about $0.70 \mathrm{MPa} /{ }^{\circ} \mathrm{C}$. Meanwhile, the stress of the rigid panel was greatly affected by the temperature, increasing $78 \%$ and $82 \%$ when the temperature increased by $15{ }^{\circ} \mathrm{C}$ on rigid panel 1 and rigid panel 2, respectively. The comparative simulation results indicated that the bending moment and shear strength of pile 1 were markedly affected by the temperature, but pile 2 and pile 3 were basically stable. Lastly, as the temperature varied, waist beam 2 had the largest change in the deflection, followed by waist beam 1; the crown beam experienced the smallest change in the deflection.

Keywords: assembled supporting structure; foundation pit; thermal stress; full-scale test; numerical simulation

\section{Introduction}

As the most important component of a foundation pit, the supporting structure is an important facility for ensuring its safety. Therefore, to ensure the construction efficiency, safety, economy, and environmental friendliness, it is significant that an appropriate supporting structure according to the characteristics of the foundation pit is chosen.

There are many types of supporting structures commonly used in foundation pits, but they differ in advantages and disadvantages. For instance, bored piles have no environmental hazards such as vibration and noise pollution during construction, and the pile body has high strength, high stiffness, and good stability. However, their installation is time-consuming and labor-intensive, resulting in slow hole formation [1,2]. Steel sheet piles are environmentally friendly, can be rapidly constructed, and have good waterproof performance; however, they are easy to corrode, so they are often used for emergency rescue and disaster relief $[3,4]$. The construction of soil nailing walls is simple, fast, and 
cost-effective; they can also make rational use of the self-stabilization ability of soil and can use soil as a component of the supporting structure, but it is difficult to apply them to areas with poor soil qualities $[5,6]$. The soil mixing walls have reliable structural strength, good water-retaining and anti-seepage performance, and they can be applied to deep foundation pits with multi-point supports. However, the interaction between mixing piles and steel supports should be further studied [7]. Diaphragm walls are a type of support with better performance because of their high rigidity and good sealing effect. However, due to their high cost, they are often used in foundation pits with high safety requirements $[8,9]$.

With the popularization of the concept of green building, the sustainable supporting structure technology of deep foundation pits has gradually become one of the key development directions of geotechnical engineering. Steel assembled section supports have the advantages of sufficient safety reserve, a short construction period, low cost, and recyclability [10-12]. Among them, steel $\mathrm{H}$-section supports are economical and efficient with a higher optimized cross-sectional area distribution and a higher reasonable strengthto-weight ratio $[13,14]$. Moreover, their interface characteristics are obviously superior to the traditional steel I-section supports, steel channel supports, and steel angle supports.

However, this type of supporting structure is significantly affected by the temperature variation. In fact, when there is a large temperature gradient, these supporting structures experience serious thermal expansion and cold contraction. Boone et al. observed that the supporting load and the temperature increase synchronously in a deep foundation pit, but they do not decrease continuously when the temperature declines. In addition, a new method was proposed for separating soil pressure and temperature pressure in foundation pit supports [15]. Massoudi developed a relationship between the stress, deformation, and temperature of an anchor in a deep foundation pit by a rotary spray support based on the measured data. The measurement results showed that increasing the temperature by $10^{\circ}$ Fahrenheit could reduce the load borne the bolt by $4.5 \mathrm{KN}$ [16]. Hashash et al. reported that with an increase in the excavation depth and the arrangement of the additional struts, the thermal load coefficients of the supports gradually decreased; in addition to soil stiffness, the thermal load coefficient was related to the stiffness of the support-soil system and the excavation stage [17]. Chapman et al. proposed an analytical formula for the thermal stress on multi-layer horizontal supports. However, it cannot distinguish the difference in the axial force on each support layer, which makes it unsuitable for deep foundation pit engineering with temperature gradients [18]. Yao et al. analyzed a steel-concrete mixed structure and found that the internal force on and the deformation of the structure were larger under the effect of the annual temperature difference; they also reported that the variation in the temperature had a greater influence on the middle span than on the side span. Therefore, the cross-sectional area and the restraint form of the braces should be adjusted reasonably to reduce this influence [19].

Most of the above studies have taken the influence of thermal stress on concrete supporting structures into account, but few are concerned with steel supporting structures. A steel assembled supporting structure, composed of a steel $\mathrm{H}$-section and a rigid panel, was proposed in this work for the foundation pit. Steel has high temperature sensitivity, and its performance is significantly affected by surrounding temperature. However, there is few studies on the influence of thermal stress on steel support structure. The full-scale test was conducted to study the effects of the temperature on the deformation of and the stress on the retaining pile, the crown beam, and the waist beam. Then, a finite element model was established, and its accuracy was verified by key parameters. Finally, the mechanical properties of the supporting structure were analyzed comprehensively by a numerical simulation. The research on the stability of this kind of foundation pit supporting structure is of great significance. 


\section{Full-Scale Test}

\subsection{Test Overview}

The test was performed on the foundation pit in the test base of the Engineering Hospital on the northeast side of the intersection of Shengyuan Road with Chuangye Avenue in Pingyu County. According to the results of the site investigation, the foundation soil was divided into six soil layers, which were mainly composed of silty clay Quaternary Late Pleistocene alluvial-diluvial (Q4al + pl). The detailed physical and mechanical parameters of the soil are listed in Table 1. The groundwater level belonged to pore diving, which existed in the fissures and pores of soil, and the water level was about $3 \mathrm{~m}$ below the ground.

Table 1. The physical and mechanical parameters of the soil layer.

\begin{tabular}{|c|c|c|c|c|c|c|}
\hline Soil Layer Name & $\begin{array}{c}\text { Soil } \\
\text { Thickness(m) }\end{array}$ & $\operatorname{Density}\left(\mathrm{g} / \mathrm{cm}^{3}\right)$ & $\begin{array}{c}\text { Compression } \\
\text { Index }\end{array}$ & Rebound Index & Stress Ratio & Void Ratio \\
\hline Plain fill & 1.3 & 1.85 & 0.080 & 0.008 & 0.90 & 0.92 \\
\hline Silty clay & 1.2 & 1.92 & 0.065 & 0.007 & 1.00 & 0.74 \\
\hline Silty clay & 3.6 & 1.94 & 0.032 & 0.048 & 0.94 & 0.80 \\
\hline Silty clay & 2.4 & 1.97 & 0.037 & 0.0052 & 0.86 & 0.83 \\
\hline Silty clay & 2.4 & 1.92 & 0.042 & 0.0061 & 1.10 & 0.70 \\
\hline Silt & 3.1 & 1.94 & 0.030 & 0.0032 & 0.86 & 0.68 \\
\hline
\end{tabular}

The test foundation pit had the dimensions $6 \mathrm{~m} \times 6 \mathrm{~m} \times 6 \mathrm{~m}$. Considering the high groundwater level, eight dewatering wells with a depth of $10 \mathrm{~m}$ and a pipe diameter of $0.5 \mathrm{~m}$ were arranged $1.5 \mathrm{~m}$ away from the foundation pit boundary. The construction was started after the monitored water level fulfilled the conditions for the excavation of foundation pit. The retaining piles adopted an HW175 section made of steel (Q345), with the dimensions $175 \mathrm{~mm} \times 175 \mathrm{~mm} \times 7.5 \mathrm{~mm} \times 11 \mathrm{~mm}$, a length of $9 \mathrm{~m}$, an insertion ratio of 0.33 , and pile spacing of $1.5 \mathrm{~m}$. The retaining piles were connected with rigid panels, which were made of Q235 steel, with the dimensions $6000 \mathrm{~mm} \times 1470 \mathrm{~mm}$ and a wall thickness of $6 \mathrm{~mm}$. A crown beam and two waist beams, which were made of an HW175 steel (Q345) section with the same specifications and had a length of $6 \mathrm{~m}$, were vertically arranged in the foundation pit. The retaining piles and the waist beams were fixed by bolts (M20), and water-stop strips were pasted between the retaining piles and the rigid panels for water insulation. A schematic diagram of the field supporting structure is shown in Figure 1, and the profile of the foundation pit is displayed in Figure 2. The physical and mechanical parameters of the supporting structure are presented in Table 2.

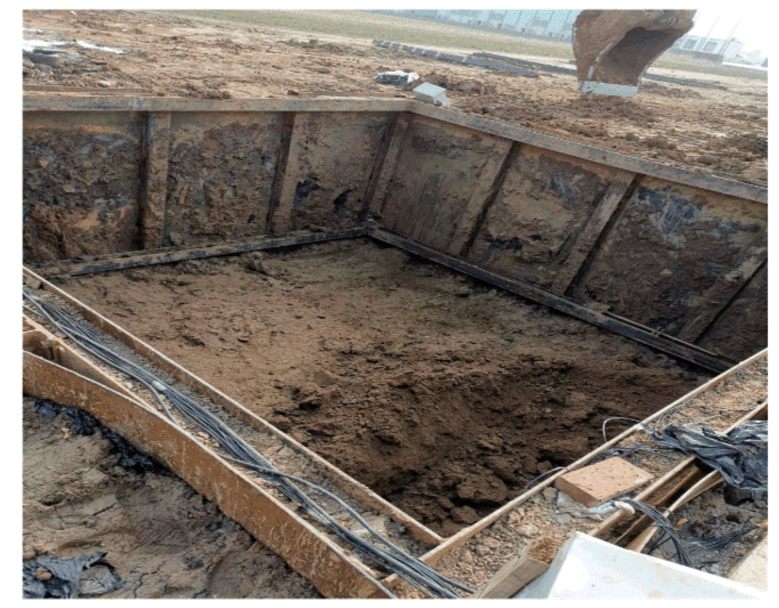

Figure 1. A schematic diagram of the field supporting structure. 


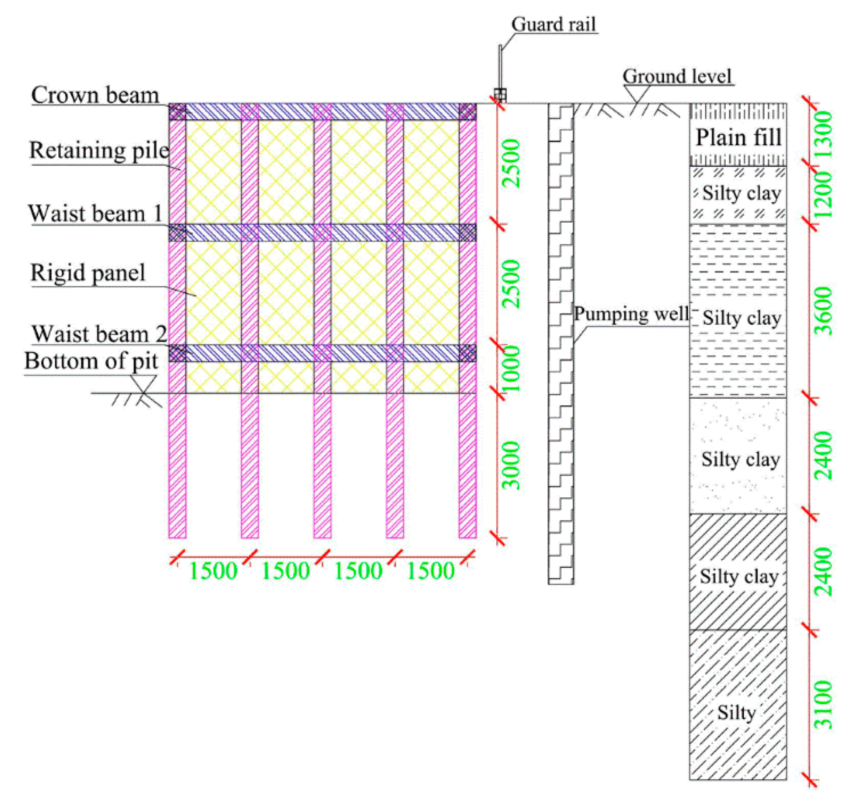

Figure 2. The profile of the foundation pit.

Table 2. The physical and mechanical parameters of the supporting structure.

\begin{tabular}{|c|c|c|c|c|c|c|}
\hline $\begin{array}{l}\text { Supporting } \\
\text { Materials }\end{array}$ & $\begin{array}{l}\text { Elastic Modulus } \\
\text { (GPa) }\end{array}$ & $\begin{array}{l}\text { Poisson's } \\
\text { Ratio }\end{array}$ & $\begin{array}{l}\text { Density } \\
\left(\mathrm{g} / \mathrm{cm}^{3}\right)\end{array}$ & $\begin{array}{l}\text { Yield Strength } \\
\text { (MPa) }\end{array}$ & $\begin{array}{c}\text { Tensile, Compressive, } \\
\text { and Bending Strength } \\
(\mathrm{MPa})\end{array}$ & $\begin{array}{l}\text { Shear Strength } \\
\text { (MPa) }\end{array}$ \\
\hline Retaining pile & 210 & 0.3 & 7.8 & 345 & 310 & 180 \\
\hline Rigid panel & 210 & 0.3 & 7.8 & 235 & 215 & 125 \\
\hline Crown beam & 210 & 0.3 & 7.8 & 345 & 310 & 180 \\
\hline Waist beam & 210 & 0.3 & 7.8 & 345 & 310 & 180 \\
\hline
\end{tabular}

\subsection{Test Scheme}

Considering that the foundation pit is an axisymmetric structure, monitoring $1 / 8$ of its area can reflect the stress on, and the deformation of, the whole supporting structure. Figure 3 depicts the layout of the monitoring points on the site of the foundation pit.

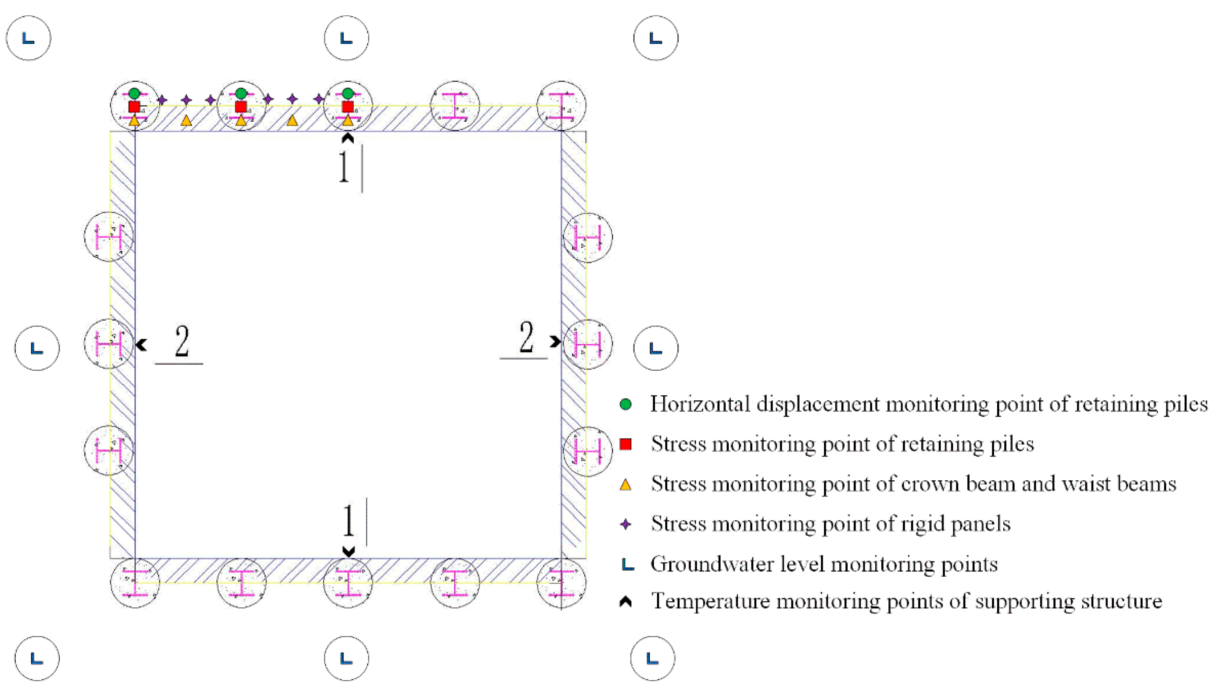

Figure 3. The layout of the monitoring points on the site of the foundation pit. 
Figure $4 \mathrm{a}$, b show that after the positions of the strain gauges were flattened, smoothed, and polished, the strain gauges were stuck to the retaining piles, the crown beam, the waist beams, and the rigid panels according to the standard operation. Then, epoxy resin and neutral silicone weather-resistant adhesive were coated on the surface of the strain gauges to protect them from scratching. Figure $4 \mathrm{c}$ exhibits the inclinometer tube tied and fixed on the retaining piles.

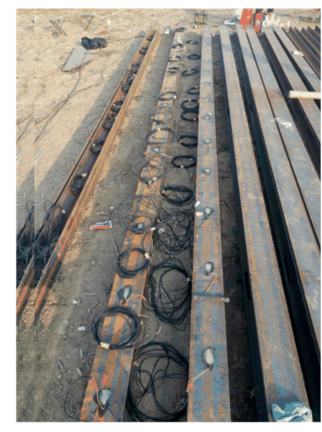

(a)

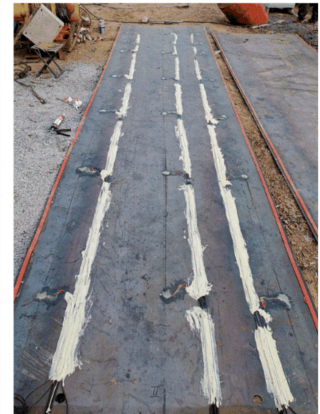

(b)

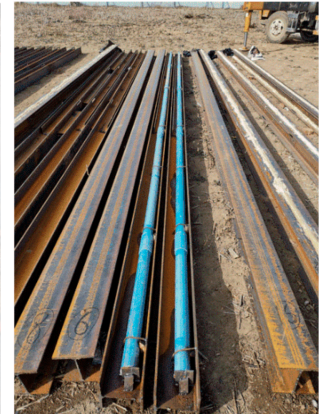

(c)

Figure 4. The layout of (a,b) stress and (c) horizontal displacement monitoring points.

\subsection{Foundation Pit Excavation}

When the actual dewatering depth reached the design value, the excavation of the foundation pit and the installation of the supporting structure started. The excavation process of the foundation pit is displayed in Figure 5. In fact, Figure 5a shows the implantation of the retaining piles and the installation of the crown beam; Figure $5 b$ depicts using a high-pressure water jet cutting technology to create a slot into the ground, and inserting a rigid panel into the slot; Figure 5 c illustrates the excavation of the first layer of the soil, and the installation of waist beam 1 ; Figure $5 \mathrm{~d}$ shows the excavation of the second layer of the soil, and the installation of waist beam 2. Finally, the foundation pit was excavated to the bottom elevation.
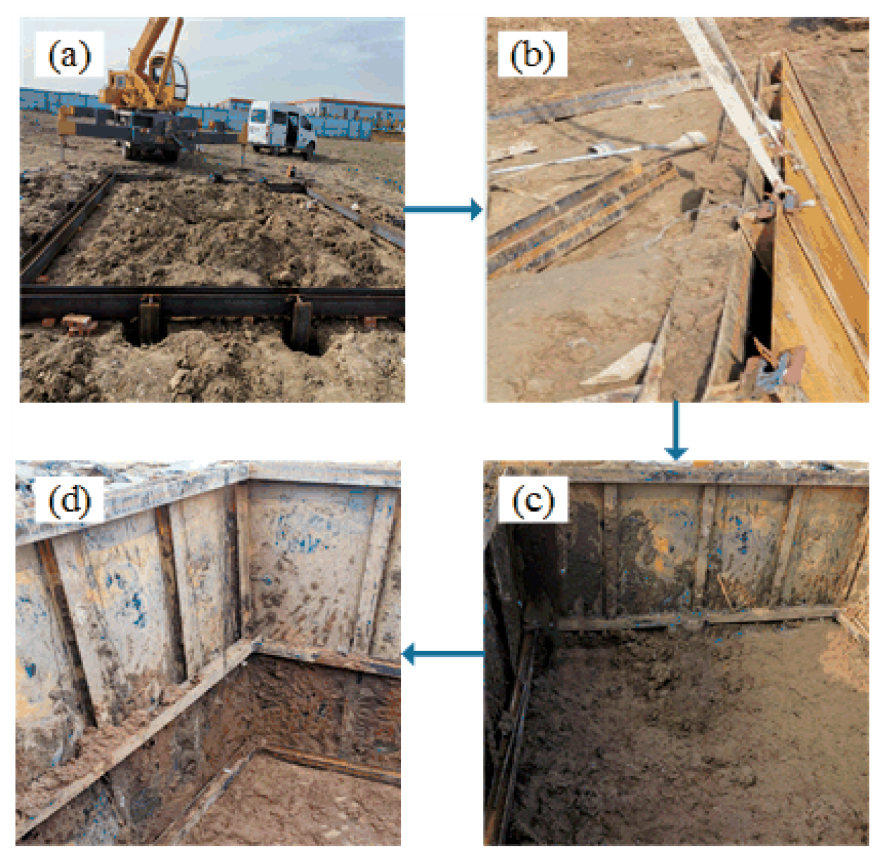

Figure 5. The excavation process of the foundation pit. (a) Implantation of the retaining piles and installation of the crown beam; (b) Insertion of the rigid panels; (c) Excavation of the first layer of the soil and the installation of waist beam 1; (d) Excavation of the second layer of the soil and the installation of waist beam 2 . 


\subsection{Data Monitoring}

After the excavation of the foundation pit, the original equilibrium state of the soil was destroyed. In order to eliminate the impact of the soil creep characteristics, stress monitoring was carried out one month after the excavation of the foundation pit was completed. The monitoring time was from February to April, when the atmospheric temperature rose from 6 to $24{ }^{\circ} \mathrm{C}$, and the surface temperature of steel varied from 8 to $27^{\circ} \mathrm{C}$, as shown in Figure 6. From 3 February to 8 February, the temperature of the supporting structure was about $10^{\circ} \mathrm{C}$; from 8 March to 15 March, the temperature of the supporting structure was about $15^{\circ} \mathrm{C}$; from 30 March to 5 April, the temperature of the supporting structure was about $20^{\circ} \mathrm{C}$; from 21 April to 25 April, the temperature of the supporting structure was about $25^{\circ} \mathrm{C}$. The average values of the strain and displacement of the supporting structure in the above period were regarded as the strain and displacement at the corresponding temperature.

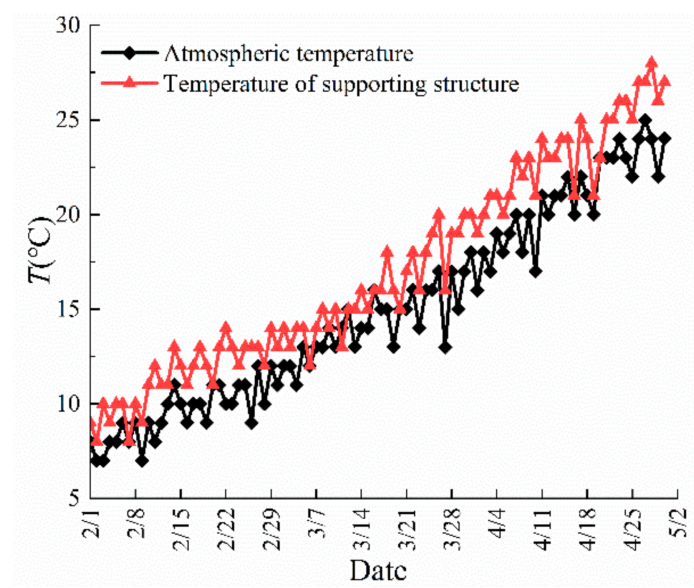

Figure 6. The variation of the temperature from February to April.

\section{Analysis of Monitoring Results}

\subsection{Displacement Analysis of Retaining Piles at Different Temperatures}

\subsubsection{Horizontal Displacement of Pile Body}

The horizontal displacements of piles 2 and 3 at different temperatures after the excavation of the foundation pit are delineated in Figure $7 \mathrm{a}, \mathrm{b}$, respectively; since the monitoring point of pile 1 was damaged, the horizontal displacement of this pile is not presented. The vertical axis represents the length of the pile $(H)$ in meters, and the horizontal axis indicates the horizontal displacement of the pile $(D)$ in millimeters. The positive sign implies that the direction of the horizontal displacement is outward along the foundation pit, and the negative sign denotes the reverse direction.

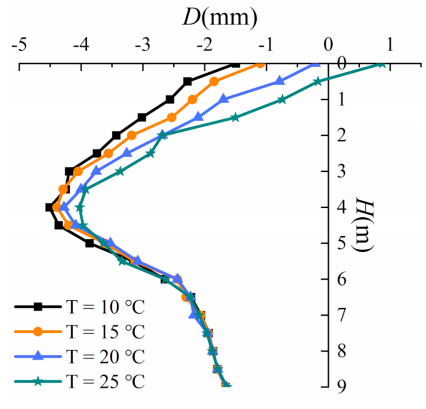

(a)

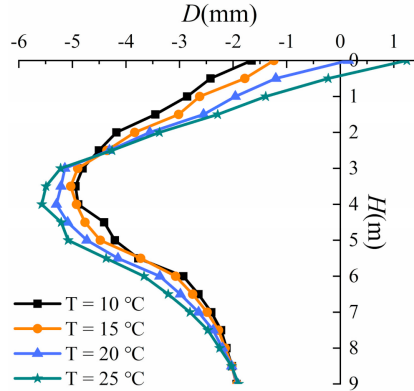

(b)

Figure 7. The displacement-temperature relationship of (a) pile 2 and (b) pile 3. 
Figure 7a shows that after the excavation of the foundation pit was completed, owing to the role of the earth pressure behind the supporting structure, pile 2 produced a displacement toward the pit, overall. The maximum displacement occurred at a depth of around $2 / 3$ of the excavation depth. Under the action of the thermal stress, the crown beam and the waist beam were elongated to produce jacking force on the retaining pile. Thus, pile 2 was displaced outside the pit, and the horizontal displacement of the pile crown changed most obviously. The horizontal displacement of the pile crown increased by $2.37 \mathrm{~mm}$ after the temperature rose by $15^{\circ} \mathrm{C}$, which played a positive role in the supporting system. However, under the excavation face, the horizontal displacement of the pile was basically stable due to the constraint of the soil.

Figure $7 \mathrm{~b}$ indicates that the deformation law of pile 3 was different from that of pile 2 , and the deformation amplitude of pile 3 was larger than that of pile 2. Pile 3 rotated around the pile body, and the pile above waist beam 1 moved outward with a temperature rise, while the pile below waist beam 1 moved further into the pit. Combined with the analysis of the horizontal displacement of waist beam 2 by the finite element method given below, this phenomenon can be well explained. The deflection of waist beam 2 increased due to the thermal stress, and its deformation form is shown in Figure 8. The end of waist beam 2 deformed out of the pit, while the middle of the beam deformed into the pit, which drove the bottom of pile 3 to move into the pit; this caused the deformation of pile 3 to consist of rigid rotation and flexural deformation, while pile 2 only experienced flexural deformation. When the temperature rose by $15^{\circ} \mathrm{C}$, the displacement of the crown of pile 3 increased by $2.90 \mathrm{~mm}$, which was more remarkable than that of pile 2 .

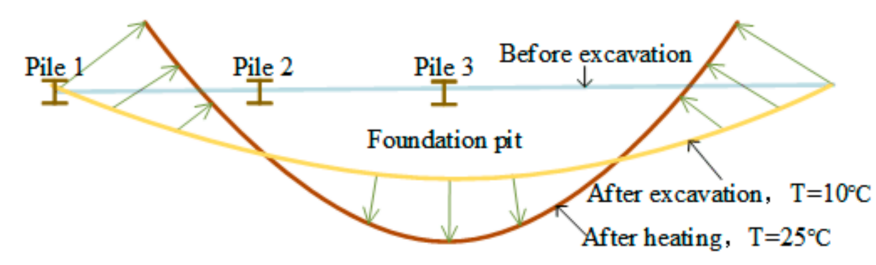

Figure 8. A schematic diagram of the deformation of waist beam 2 .

\subsubsection{Horizontal Displacement Analysis of Pile Crown}

The horizontal displacement of the pile crown is an important index of characterizing the safety of the supporting structure. The variation in the horizontal displacement of the pile top with the time measured on site is delineated in Figure 9. It is not difficult to find that the pile crown was displaced into the pit at the initial stage of the excavation, and pile 3 was located in the middle of the foundation pit, which led to the maximum displacement, thereby showing an obvious time-space effect. In the subsequent heating stage, the pile crown was displaced to the outside of the pit, and the horizontal displacement of the pile crown was highly consistent with the trend of change in the temperature. By the end of monitoring, the horizontal displacement of the crown of pile 1,2, and 3 increased by $1.15,2.81$, and $3.42 \mathrm{~mm}$, respectively. It can also be seen that the pile in the middle of the foundation pit was most affected by the temperature. It was noted that before mid-March, the horizontal displacement of the pile crown enlarged slowly with the temperature. After mid-March, the increasing rate of the horizontal displacement of the pile crown rose with the temperature because the rate of the local temperature rise increased; however, the daily temperature difference declined after mid-March, which led to the increase in the horizontal displacement rate of the pile crown. 


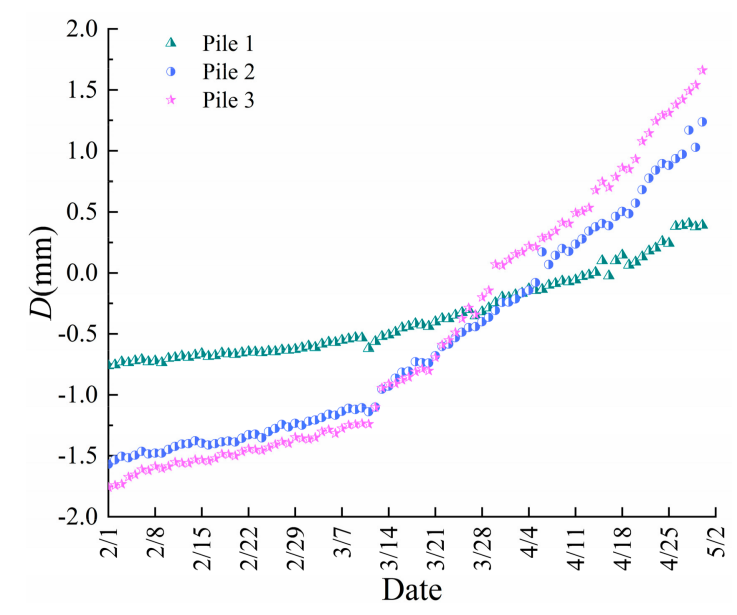

Figure 9. The horizontal displacement of the crown of the retaining piles.

In Figure 10, the horizontal axis represents the temperature difference $(\Delta \mathrm{T})$, and the vertical axis denotes the ratio of the increment in the horizontal displacement caused by the temperature variation to the excavation depth $(\Delta \mathrm{D} / \mathrm{H})$. Hu et al. [20] analyzed the stress on, and the deformation of, the diaphragm wall of a foundation pit by a numerical simulation. Their results showed that the slope of the curve of $\Delta \mathrm{D} / \mathrm{H}$ versus $\Delta \mathrm{T}$ was 0.1335 . The slope was large, which might be due to the large excavation section of the foundation pit and the wider temperature influence range. Wu et al. [21] and Liu et al. [22] derived the calculation formula correlating the temperature variation with the displacement of the support structure, and demonstrated that the slope of the curve of $\Delta \mathrm{D} / \mathrm{H}$ versus $\Delta \mathrm{T}$ ranged from 0.0043 to 0.0079 and from 0.0020 to 0.0078 , respectively. The growth rates were too small because the method simplified some important factors in practical engineering. In this paper, the slope of the curve of $\Delta \mathrm{D} / \mathrm{H}$ versus $\Delta \mathrm{T}$ was in the range of 0.1313 to 0.322 , which is obviously larger than the one reported by other scholars. The reason is that the foundation pit in this work used steel $\mathrm{H}$-section beams and rigid panels as the supporting structure, and the temperature variation had a more significant impact on the whole supporting system. Therefore, close attention should be paid to the safety of the steel supporting structures in areas with a high temperature difference.

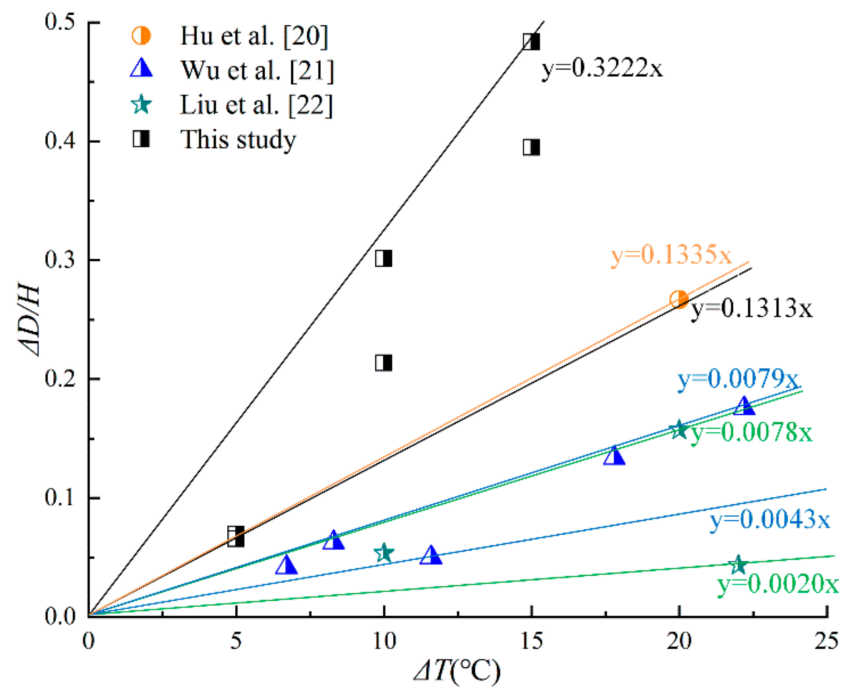

Figure 10. The relationship between $\Delta \mathrm{D} / \mathrm{H}$ and $\Delta \mathrm{T}$. 


\subsection{Stress Analysis of Supporting Structure at Different Temperatures}

\subsubsection{Stress Data Processing Method}

The strain gauges adopted a $45^{\circ}$ rectangular strain rosette for data collection as displayed in Figure 11. The resistance in all the directions of each strain gauge is $120 \Omega$. The maximum principal stress $(\sigma 1)$ and the minimum principal stress $(\sigma 2)$ on each measuring point are expressed in:

$$
\begin{aligned}
& \sigma_{1}=\frac{E}{2(1-\mu)}\left(\varepsilon_{0^{\circ}}+\varepsilon_{90^{\circ}}\right)+\frac{E}{2(1+\mu)} \sqrt{\left(\varepsilon_{0^{\circ}}-\varepsilon_{45^{\circ}}\right)^{2}+\left(\varepsilon_{45^{\circ}}-\varepsilon_{90^{\circ}}\right)^{2}} \\
& \sigma_{2}=\frac{E}{2(1-\mu)}\left(\varepsilon_{0^{\circ}}+\varepsilon_{90^{\circ}}\right)-\frac{E}{2(1+\mu)} \sqrt{\left(\varepsilon_{0^{\circ}}-\varepsilon_{45^{\circ}}\right)^{2}+\left(\varepsilon_{45^{\circ}}-\varepsilon_{90^{\circ}}\right)^{2}}
\end{aligned}
$$

where $E$ and $\mu$ are the elastic modulus and Poisson's ratio of the material, respectively; $\varepsilon_{0^{\circ}}$, $\varepsilon_{45^{\circ}}$, and $\varepsilon_{90^{\circ}}$ represent the strains in $0^{\circ}, 45^{\circ}$, and $90^{\circ}$ directions, respectively.

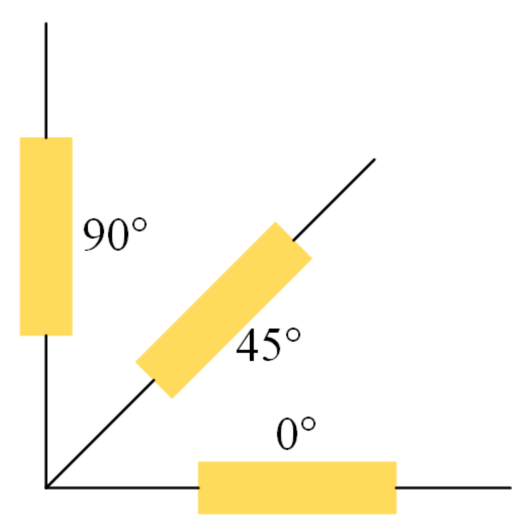

Figure 11. A schematic diagram of a $45^{\circ}$ rectangular strain rosette.

$\mathrm{H}$-section steel is a plastic material. The equivalent stress $(\sigma)$ on each measuring point can be calculated by the fourth strength theory, which can well express the mechanical performance of the supporting structure; the calculation formula is defined as:

$$
\sigma=\frac{1}{\sqrt{2}} \sqrt{\left(\sigma_{1}-\sigma_{2}\right)^{2}+\left(\sigma_{2}-\sigma_{3}\right)^{2}+\left(\sigma_{3}-\sigma_{1}\right)^{2}}
$$

where $\sigma_{1}$ and $\sigma_{2}$ represent the maximum and minimum principal stress, respectively, and $\sigma_{3}$ is zero.

\subsubsection{Stress Analysis of Retaining Piles at Different Temperatures}

A total of 18 strain gauges were arranged on each retaining pile every $0.5 \mathrm{~m}$, and the top strain gauge was shifted down by $0.2 \mathrm{~m}$ due to the reserved hoisting hole at the pile crown. The measuring points on retaining pile 1 , retaining pile 2 , and retaining pile 3 were indicated by A1-A18, B1-B18, and C1-C18, respectively, as shown in Figure 12. The measured data were analyzed, and the stress-temperature relationship curves of retaining piles 1, 2, and 3 are drawn in Figure 13a-c, respectively. 


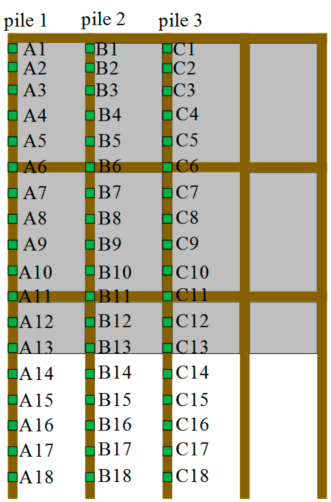

Figure 12. The layout of the strain gauges installed on the retaining piles.

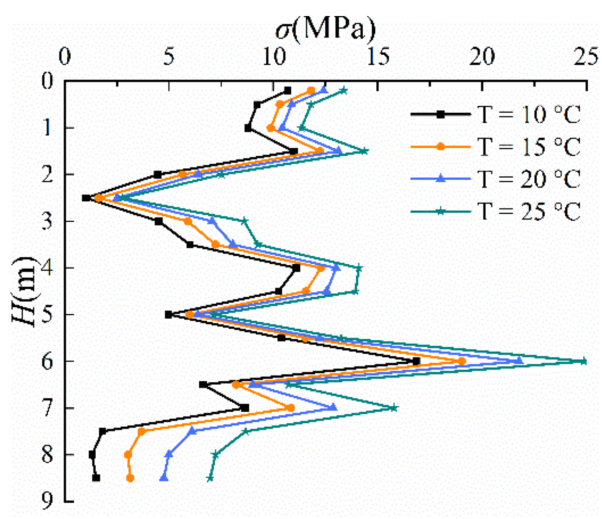

(a)

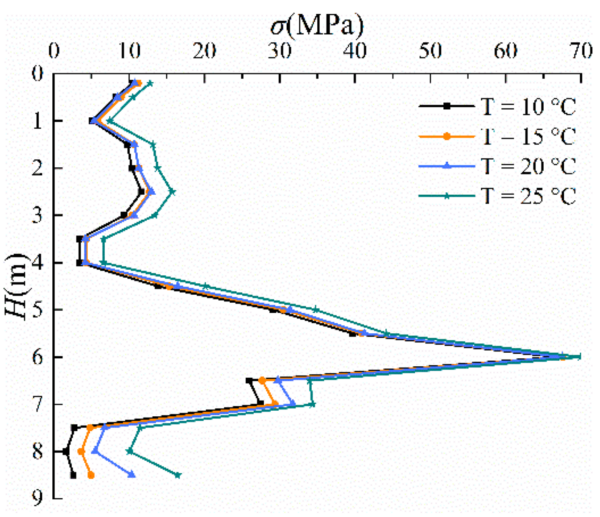

(b)

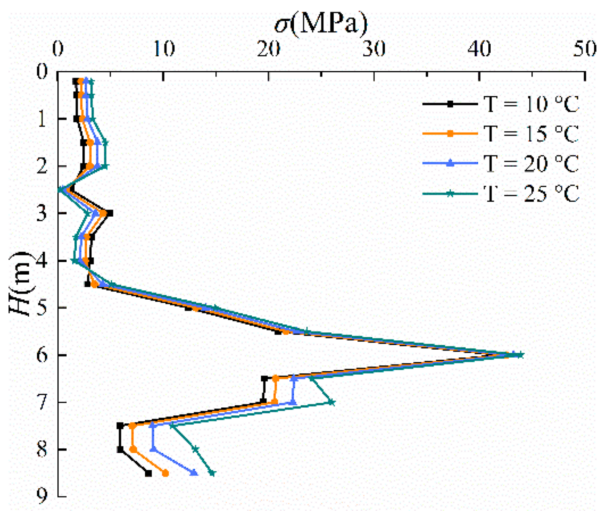

(c)

Figure 13. The stress-temperature relationship of (a) pile 1, (b) pile 2, and (c) pile 3.

It can be seen in Figure 13 that after the excavation of the foundation pit was completed, the retaining pile deformed to the pit. Due to the maximum displacement at the crown of retaining pile 3 and the minimum displacement at the crown of retaining pile 1 , the stress on point $\mathrm{C} 1$ was the minimum, while that on point $\mathrm{A} 1$ was the maximum. The maximum stress occurred on the excavation face, and B13 > C13 > A13.

When the temperature rose from 10 to $25^{\circ} \mathrm{C}$, higher thermal stress was released due to the large displacement of the pile crown. The stress on points $\mathrm{Al}, \mathrm{B} 1$, and $\mathrm{C} 1$ increased by $2.68,2.30$, and $1.44 \mathrm{MPa}$, respectively, but the stress basically did not change. However, the pile bottom was embedded in the soil, and there was almost no displacement; thus, it was easier for the pile bottom to accumulate stress. The stress on points A18, B18, and C18 enlarged by 5.47, 13.81, and $6.00 \mathrm{MPa}$, respectively, which was even greater than the increment in stress caused by the excavation of the foundation pit. The stress on the 
other measuring points also increased with the temperature rise, which was obviously unfavorable for the stress on the retaining piles.

Due to the corner effect, the stress on point A13 of pile 1 increased by $8.02 \mathrm{MPa}$ after the temperature rose by $15{ }^{\circ} \mathrm{C}$. Its increase amplitude even exceeded the stress on the bottom of the pile, which was obviously different from the variation law of the corresponding positions of piles 2 and 3 . The stress curves of piles 2 and 3 were similar, but the stress on pile 2 was greater than that on pile 3 . Under the excavation and temperature load, the stresses on piles 2 and 3 was finally 69.95 and $43.89 \mathrm{MPa}$, respectively, both of which fulfilled the allowable stress on steel.

\subsubsection{Stress Analysis of Crown Beam and Waist Beams at Different Temperatures}

The crown beam and the waist beams were tied to the retaining piles to form a supporting system together. If the supporting structure is damaged by concentrated stress, the retaining piles cannot form a whole, leading to the collapse of the foundation pit. Therefore, it was necessary to study the forms of the stress on the crown beam and the waist beams. The strain monitoring points were located at a position of $0,0.75,1.5,2.25$, and $3 \mathrm{~m}$ on the crown beam and the waist beams, and the monitoring points on the crown beam, waist beam 1, and waist beam 2 were indicated by D1-D5, E1-E5, and F1-F5, respectively, as depicted in Figure 14. The supporting structure was axisymmetric, and the overall stress on the crown beam and the waist beams can be obtained by a mirror image. The stress-temperature relationship curves of the crown beam, waist beam 1, and waist beam 2 are plotted in Figure 15a-c, respectively.

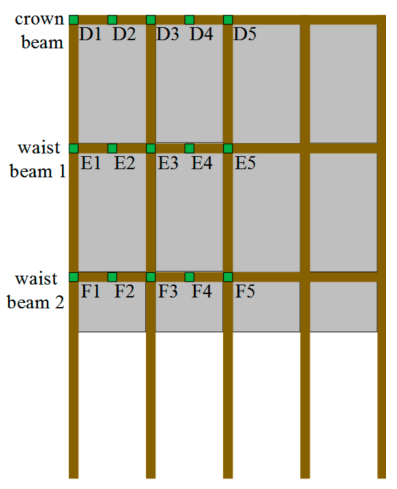

Figure 14. The layout of the strain gauges installed on the crown beam and the waist beams. 


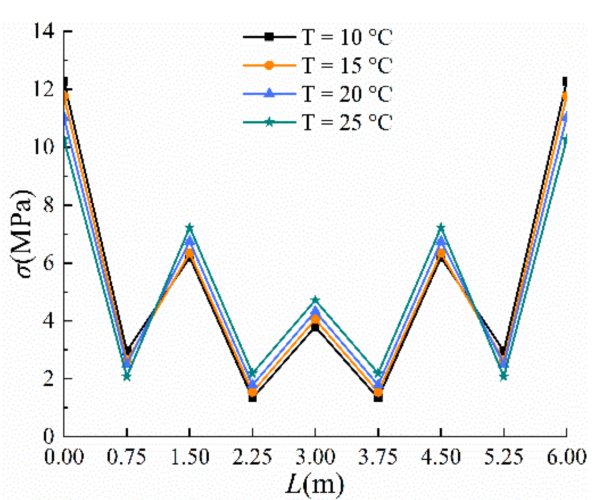

(a)

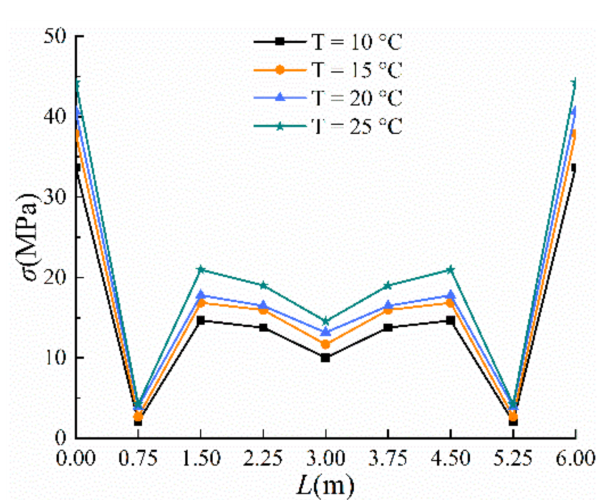

(b)

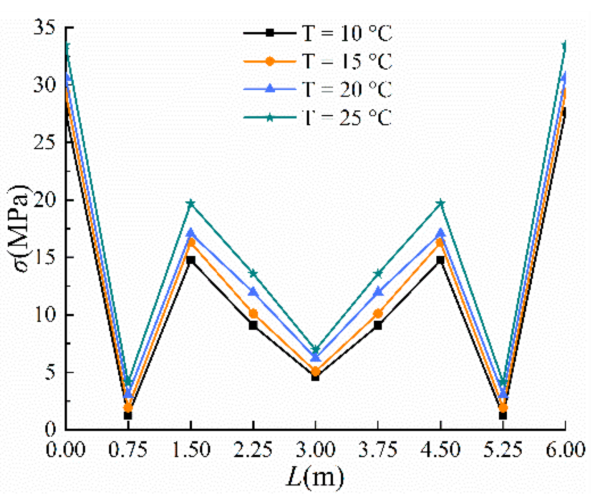

(c)

Figure 15. The stress-temperature relationship of (a) the crown beam, (b) waist beam 1, and (c) waist beam 2 .

It can be seen in Figure 15a that when the temperature rose, the stress on points D1 and D2 gradually decreased, while the stress on points D3-D5 gradually increased. The analysis shows that when the temperature rose, the crown beam expanded, which led to further deformation out of the foundation pit and enlarged the stress on the crown beam. The deformation of the adjacent crown beam outside the foundation pit led to the release of the stress on the side crown beam. As a result, the stress on the end of the crown beam decreased with the temperature rise, while the stress on the middle of the crown beam increased. When the temperature rose from 10 to $25^{\circ} \mathrm{C}$, the maximum change in the stress on point D1 was $2.00 \mathrm{MPa}$. Hence, it can be concluded that the temperature rise slightly influences the stress on the crown beam.

Figure $15 \mathrm{~b}$ demonstrates that after the excavation of the foundation pit, waist beam 1 was deformed into the pit. As the temperature rose, the waist beam was heated, expanded, and further deformed toward the inside of the foundation pit, which resulted in increased stress on waist beam 1 . When the temperature rose from 10 to $25^{\circ} \mathrm{C}$, the increment in the measured stress on points E1-E5 was 10.57, 2.17, 6.33, 5.23, and 4.52 MPa, respectively. It can be seen that the stress on point $\mathrm{E} 1$ was significantly affected by the temperature and increased by $0.70 \mathrm{MPa} /{ }^{\circ} \mathrm{C}$. After the temperature rose by $15^{\circ} \mathrm{C}$, the measured stress on point E1 reached $44.25 \mathrm{MPa}$, which was far smaller than the allowable stress on the HW175 steel section.

The stress variation law of each measuring point in Figure 15c is basically similar to that in Figure 15b. When the temperature rose from 10 to $25^{\circ} \mathrm{C}$, the stress values on points F1-F5 increased by $5.79,2.89,4.93,4.51$, and $2.37 \mathrm{MPa}$, respectively, which were all smaller than the corresponding increments in stress on waist beam 1. Hence, waist beam 2 was not so severely affected by the temperature as waist beam 1 . The analysis confirmed that waist beam 2 was deeply buried and shortly had a short-time exposure to sunlight, so it was less affected by the temperature compared to waist beam 1 . 


\subsubsection{Stress Analysis of Rigid Panels at Different Temperatures}

The rigid panels are an important part of the support system and can resist the pressure of the soil and water. If a rigid panel is damaged due to excessive deformation, the soil behind it is likely to pour into the foundation pit, causing delays in the construction period and casualties. The stress on the middle row of rigid panel 1 and rigid panel 2 was selected for analysis, and the monitoring points were represented by G1-G7 and H1-H7, respectively, as shown in Figure 16. The stress curves of the rigid panels versus the temperature are delineated and shown in Figure 17.

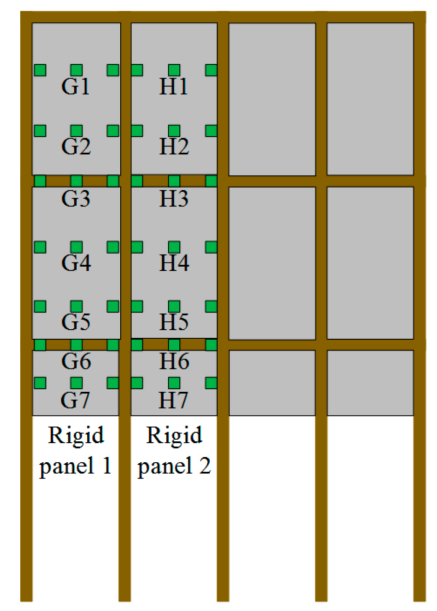

Figure 16. The layout of the strain gauges installed on the rigid panels.

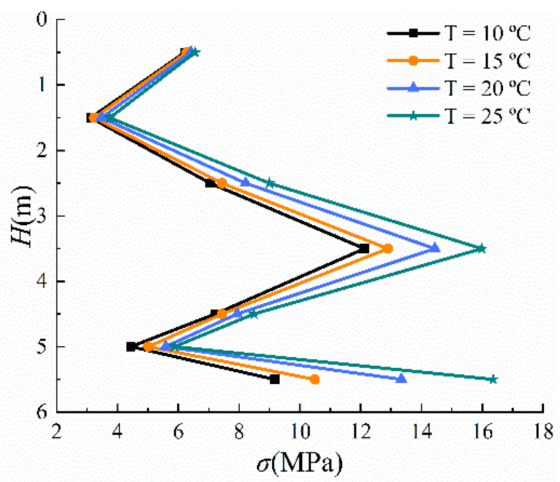

(a)

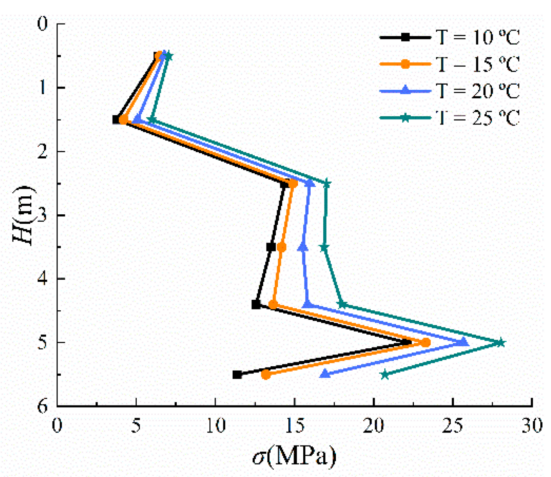

(b)

Figure 17. Stress-temperature relationship curve of the (a) rigid panel 1, (b) rigid panel 2.

Figure 17a shows that the stress on rigid panel 1 increased with the temperature rise. When the temperature rose from 10 to $25^{\circ} \mathrm{C}$, the stress on points $\mathrm{G} 1$ and $\mathrm{G} 7$ enlarged by 0.33 and $7.19 \mathrm{MPa}$, respectively, corresponding to an increment of $5 \%$ and $78 \%$, respectively. The variation in the stress on the bottom of rigid panel 1 was significantly larger than that in the stress on the top of rigid panel 1 because the rigid panel and the retaining piles formed a supporting system, and the displacement of the retaining piles also gave rise to the displacement of the rigid panel; thus, the top of the rigid panel released a large amount of stress. The bottom of the rigid panel was constrained by the soil and waist beam 2, resulting in a large amount of stress on the panel.

Figure $17 \mathrm{~b}$ is basically similar to Figure $17 \mathrm{a}$. After raising the temperature to $15^{\circ} \mathrm{C}$, the stress on points $\mathrm{H} 1$ and $\mathrm{H} 7$ increased by 0.68 and $9.34 \mathrm{MPa}$, respectively, corresponding to an increment of $11 \%$ and $82 \%$, respectively. The increment in the stress on rigid panel 2 was slightly larger than that in the stress on rigid panel 1 . The analysis confirmed that the 
deformation of rigid panel 2 was larger than that of rigid panel 1 because it was closer to the middle of the foundation pit, which led the stress on rigid panel 2 to increase more rapidly.

\section{Three-Dimensional Finite Element Model}

To verify the validity of the full-scale field test monitoring data and further study the influence of the thermal stress on the steel assembled supporting structure of the foundation pit, a three-dimensional numerical model matching the full-scale field test was established by using ABAQUS 6.14/Standard module. In the process of the finite element simulation, the surface temperature of the supporting structure was considered to be uniformly distributed, and the influence of the soil rheology and groundwater was not taken into account.

\subsection{Soil Model}

Considering that the influence of the length and width of the foundation pit was three to five times that of the depth of the pit in the model [23,24], the length and width of the foundation pit were set at $50 \mathrm{~m}$, and its depth was set at $40 \mathrm{~m}$. The modified Cambridge model was adopted for the soil, and the parameters of the test site given in Table 1 were used for the soil layer. In order to improve the accuracy of the calculations, the soil within and around the foundation pit was processed by grid encryption, while the grids far away from the foundation pit were processed by transition; also, the grid size gradually increased from the inside to the outside of the foundation pit. The grids adopted C3D8R elements with hourglass control. The displacement of the bottom of the soil in the three directions and the normal displacement around the soil were restricted. Because the mechanical properties of the soil were not almost affected by the temperature, the effect of the temperature on the soil was not taken into account to simplify the calculations. The structure of the calculation grids of the soil is depicted in Figure 18.

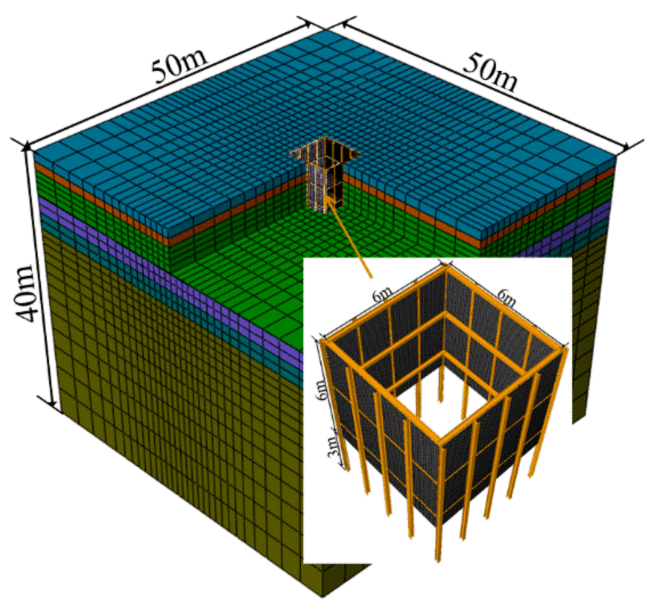

Figure 18. The structure of the calculation grids of the soil mass.

\subsection{Supporting Structure Model}

The size and shape of the supporting structure in the model were consistent with those in the field test. A B21 element, i.e., a two-node, spatial, linear beam element, was selected for the retaining piles, the crown beam, and the waist beams. An S4R element, which is a four-node, curved, thin shell element, was used for the rigid panel. The coefficient of thermal expansion of the steel section was $1.2 \times 10^{-5}$. The material parameters of the supporting structure are selected from Table 2.

\subsection{Contact Model}

An embedded constraint was chosen for the retaining piles, and binding contact was assumed between the retaining piles and the crown beam and between the waist beams 
and the rigid panel. Surface-to-surface contact was presumed between the soil and the rigid panel, and "hard" contact was adopted in the normal contact, indicating that normal pressure could only be transmitted between the two contact surfaces when they were not separated. The "penalty" function was used tangentially. Xu et al. studied that the coefficient of friction $(\mu)$ between steel and soil varies from 0.2 to 0.4 [25]. Considering that the surface of the rigid panel was relatively flat, $\mu$ was set at 0.25 in this work.

\subsection{Excavation Steps of Foundation Pit}

According to the supporting structure and the excavation steps of the foundation pit, the simulation calculations were carried out, as illustrated in Figure 19.

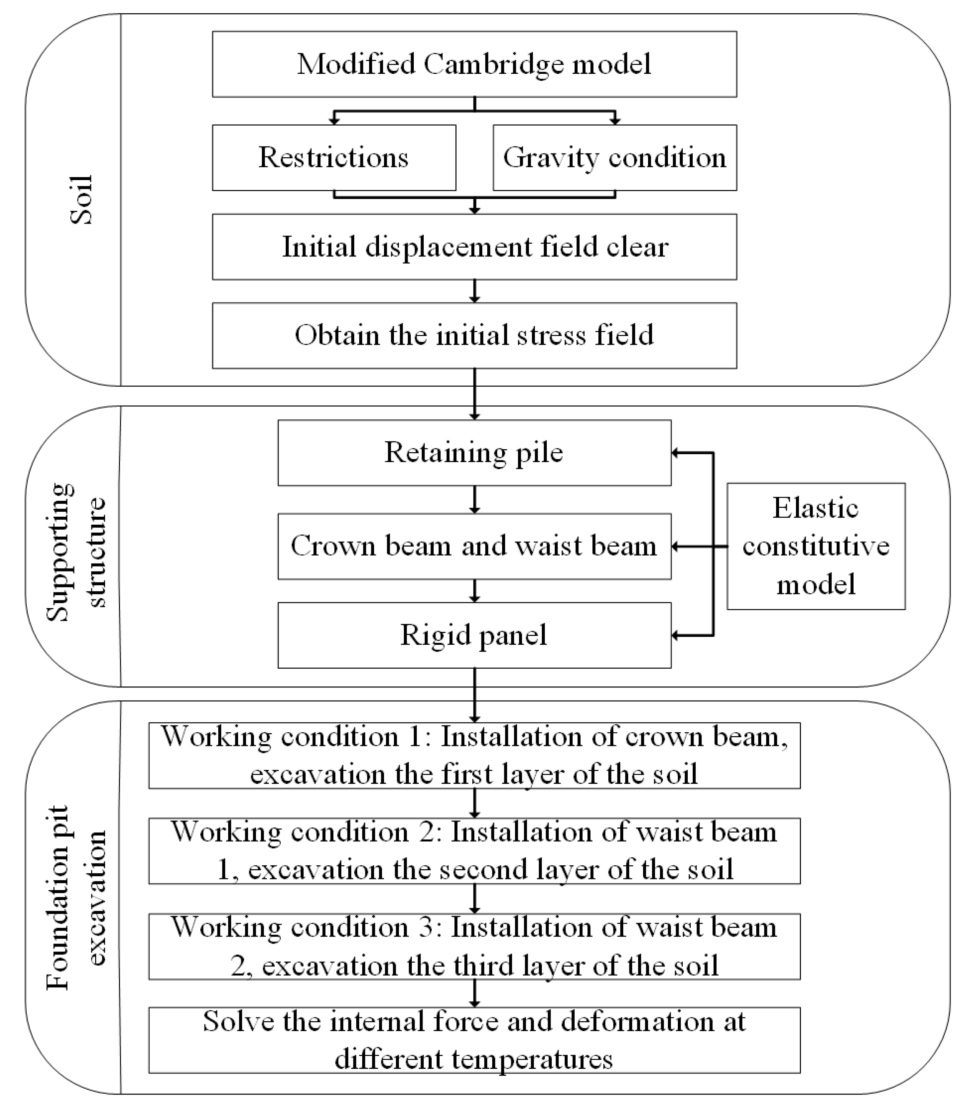

Figure 19. The flow chart of the modeling and calculations.

\subsection{Temperature Simulation}

Since steel was much more affected by the temperature than the soil, only the coefficient of thermal expansion of the retaining piles, the crown beam, the waist beams, and the rigid panels $\left(\alpha=1.2 \times 10^{-5}\right)$ was defined when setting the material parameters. Then, an analysis step of the temperature was created in the analysis step manager, and the temperature of the supporting structure was maintained constantly during the excavation of the foundation pit. Finally, after the excavation of the foundation pit, the field was predefined by changing the specified temperature in advance [26].

\section{Analysis of Simulation Results}

\subsection{Field Monitoring and Numerical Validation}

In order to verify the accuracy of the finite element model, the measured and simulated values of the horizontal displacement of pile 3 and the stress on waist beam 1 at a temperature of 10 and $25^{\circ} \mathrm{C}$ were extracted and compared, as shown in Figure 20a,b, respectively. 


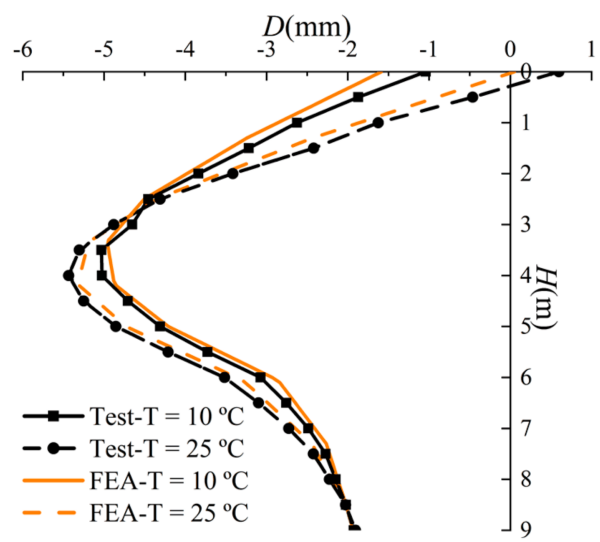

(a)

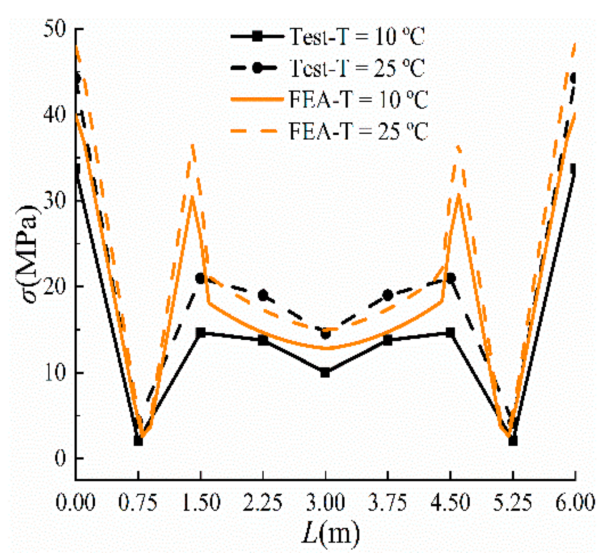

(b)

Figure 20. Comparison between the measured and simulated values: (a) The horizontal displacement of pile $3 ;(\mathbf{b})$ the stress on waist beam 1 .

Figure 20a demonstrates that after the temperature increased by $15{ }^{\circ} \mathrm{C}$, the measured horizontal displacement of the pile crown changed from -1.78 to $0.84 \mathrm{~mm}$, which increased by $2.63 \mathrm{~mm}$. The simulated horizontal displacement of the pile crown varied from -1.04 to $0.60 \mathrm{~mm}$, resulting in an increment of $1.64 \mathrm{~mm}$. Thus, the measured values were larger than the simulated ones, which might be due to the impact of continuous precipitation during monitoring on the displacement of the retaining piles. Additionally, the groundwater factor was not considered in the simulation, which led to the difference between the two; however, the deviation value was not large.

Figure $20 \mathrm{~b}$ reveals that the simulated values were all larger than the experimental ones, and the stress on points E1 and E3 was quite different. This may be because the waist beam and the retaining pile were bolted during the test, and they might be dislocated during the excavation of the foundation pit, thereby releasing certain stress. The simulation used binding contact, which fundamentally eliminated the influence of mutual dislocation, so the simulation values were slightly larger than the experimental ones. The measured and simulated stress on point E1 increased by 10.57 and $7.98 \mathrm{MPa}$, respectively, after the temperature rose by $15{ }^{\circ} \mathrm{C}$; the simulated values were lower than the measured ones. The analysis showed that it took a long time for the temperature to rise from 10 to $25^{\circ} \mathrm{C}$ during the test. Although the stress monitoring was performed one month later to reduce the influence of the soil creep characteristics, it was not removed completely. However, the numerical simulation was a transient process, which only considered the impact of the change in the temperature, so the simulated increment in the stress was smaller than the actual one.

Although there was a certain difference between the measured values and the simulated ones, it was within an acceptable range, and the trends of the measured and simulated deformation were basically consistent. Therefore, as long as the selected parameters are suitable, it is feasible to analyze the impact of the thermal stress on the supporting structure of the foundation pit by the finite element method, which can provide a frame of reference for future practical projects.

\subsection{Impact of Temperature on Bending Moment of Retaining Piles}

According to Figure 21, the maximum bending moment $(B M)$ of the retaining pile occurred on the excavation face after the excavation of the foundation pit was completed. After the temperature rose by $15^{\circ} \mathrm{C}$, due to the constraints of the crown beam and the waist beam, the absolute value of bending moment at the corresponding part of the retaining pile increased relatively. The bending moment of the retaining pile body below the excavation face changed most owing to the constraints of the soil on both sides. The increment in the bending moment of piles 1,2 , and 3 on the excavation face was 2.63, 
-0.74 , and $-0.83 \mathrm{KN} \cdot \mathrm{m}$, respectively. It can be seen that the temperature rise increased the maximum positive bending moment of pile 1 , but reduced the maximum positive bending moments of piles 2 and 3 . The bending moment of pile 1 was obviously more affected by the temperature than that of piles 2 and 3 . Under the temperature effect, the maximum bending moment reached $11.34 \mathrm{KN} \cdot \mathrm{m}$. The bending moment of the retaining pile can be expressed by:

$$
M_{\text {max }}=\sigma \times W_{x}=310 \times 10^{6} \times 334 \times 10^{-6} \approx 104 \mathrm{KN} \cdot \mathrm{m}
$$

where $\sigma$ represents the allowable stress, and $W_{x}$ is the bending cross-sectional coefficient.

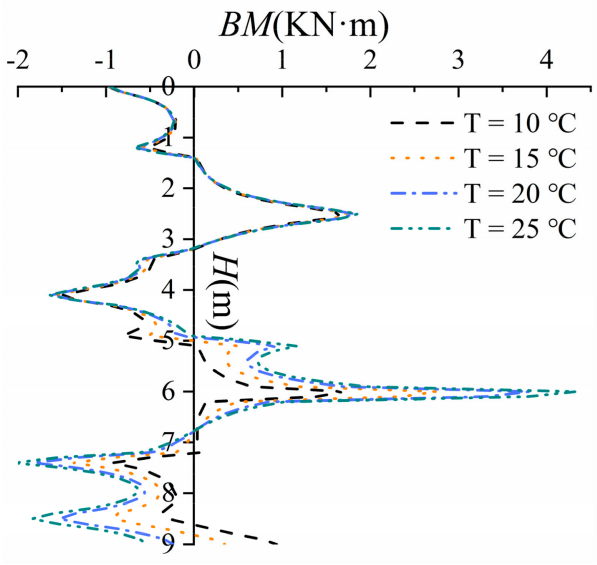

(a)

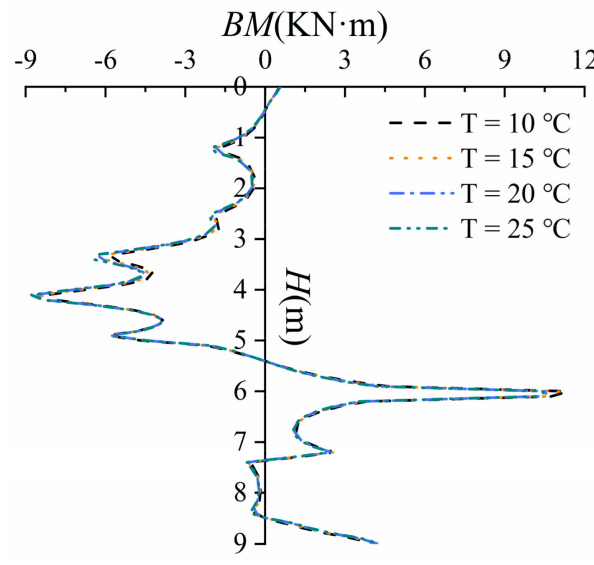

(b)

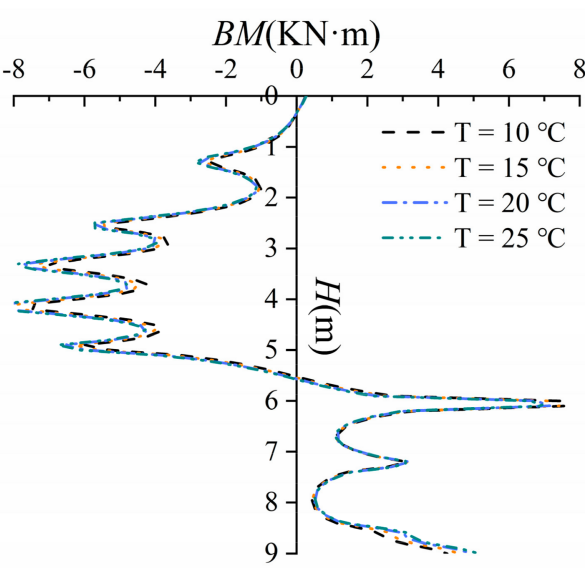

(c)

Figure 21. The bending moment (BM)-temperature relationship of (a) pile 1, (b) pile 2, and (c) pile 3.

This equation confirms that the bending moment of the retaining pile is within a reasonable range.

\subsection{Impact of Temperature on Shear Force of Retaining Piles}

Figure 22 demonstrates that the shear force $(S F)$ on the retaining piles was a positive and negative staggered phenomenon. The distribution of the shear force on retaining pile 1 was different from that of the shear force on retaining piles 2 and 3 due to the corner effect. When the temperature rose by $15^{\circ} \mathrm{C}$, the shear force on the retaining pile enlarged to resist the deformation of the pile. The maximum change in the shear force on piles 1,2, and 3 was $17.98,4.21$, and $6.47 \mathrm{KN}$, respectively, indicating the most significant change in the shear force on pile 1 and the negligible effect of the temperature on piles 2 and 3 . The maximum 
shear force on the retaining piles was $59.21 \mathrm{kN}$ under the action of the temperature rise. The shear strength of the retaining piles can be calculated by:

$$
F_{s}=A \times F_{v}=51.43 \times 10^{-4} \times 180 \times 10^{6} \approx 926 \mathrm{KN}
$$

where $A$ is the cross-sectional area of the HW175 section, and $F_{v}$ indicates the shear strength of Q345 steel.

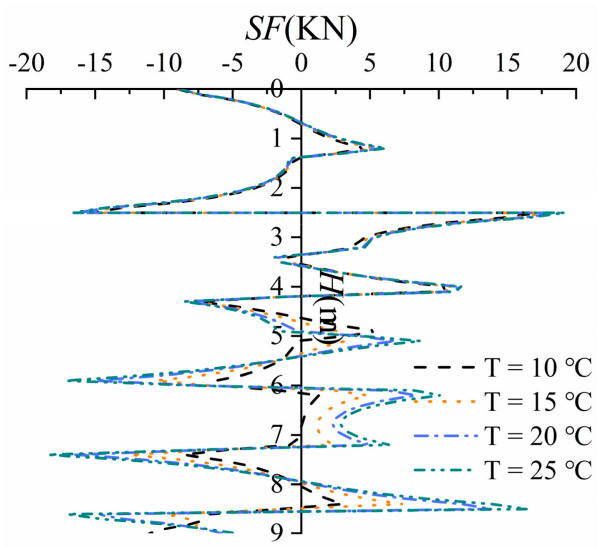

(a)

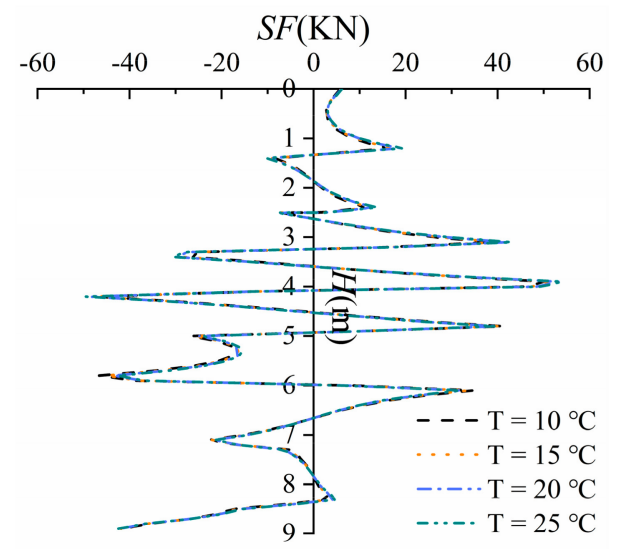

(b)

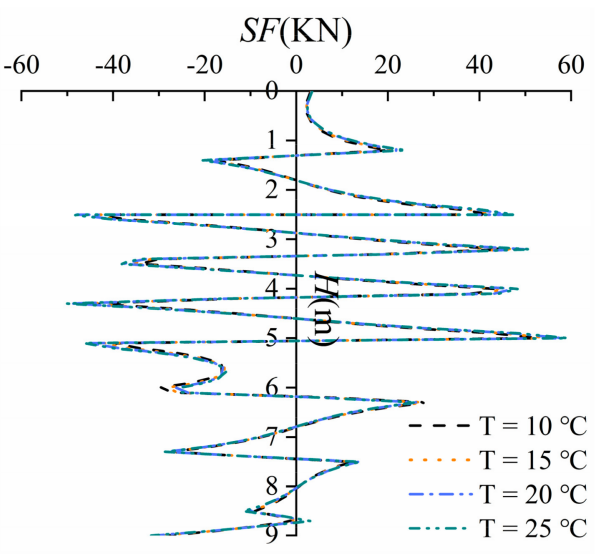

(c)

Figure 22. The shear force (SF)-temperature relationship of (a) pile 1, (b) pile 2, and (c) pile 3.

This equation confirms that the shear force on the retaining pile is within an allowable strength range of the materials.

\subsection{Impact of Temperature on Horizontal Displacement of Crown Beam and Waist Beams}

Since the crown beam and the waist beams were connected to the retaining piles, the displacements of the crown beam and the waist beams were inevitably affected by the retaining piles. Figure 23 indicates that after the temperature rose, the crown beam and waist beam 1 moved outside the foundation pit, while the middle of waist beam 2 moved inside the pit, which was consistent with the measured displacement curves of the retaining piles. Due to the small earth pressure behind the pile, the overall displacement of the crown beam was toward the outside of the pit; the overall average displacement of the crown beam was about $0.95 \mathrm{~mm}$, and it did not basically deflect. Because of the jacking force on the adjacent waist beam, the end displacement of waist beam 1 was significantly larger than its middle displacement. Indeed, the end displacement of waist beam 1 could reach $0.86 \mathrm{~mm}$, while the displacement of the middle point of it was lower than $0.1 \mathrm{~mm}$. 
Moreover, its deflection enlarged with the temperature rise. The end displacement of waist beam 2 was completely in the opposite direction of its middle displacement; in fact, the end displacement of waist beam 2 was $0.83 \mathrm{~mm}$, while the displacement of the middle point of it was $-0.32 \mathrm{~mm}$. The displacement of the middle point of waist beam 2 was larger because it was not restricted by soil. Moreover, its deflection was most severely affected by the temperature.

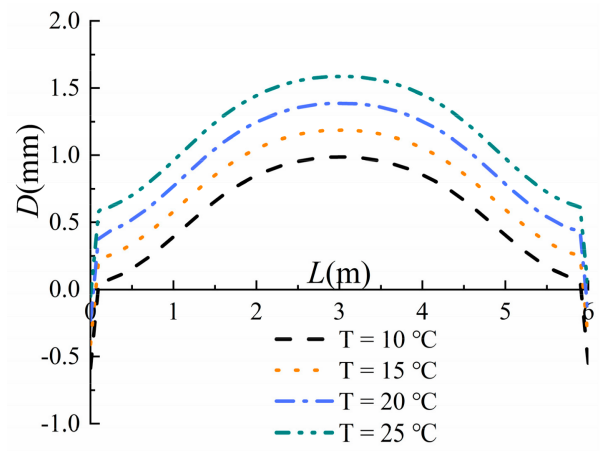

(a)

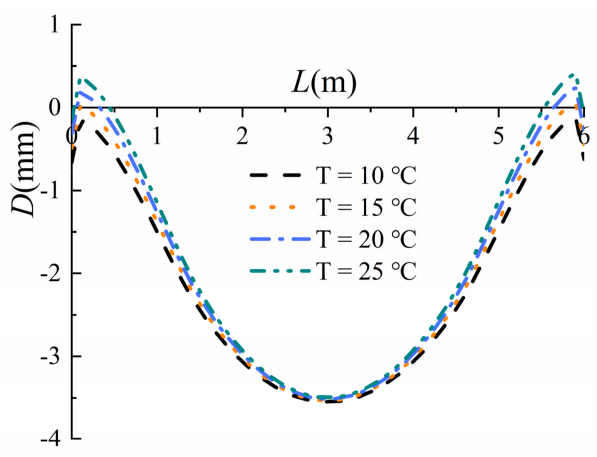

(b)

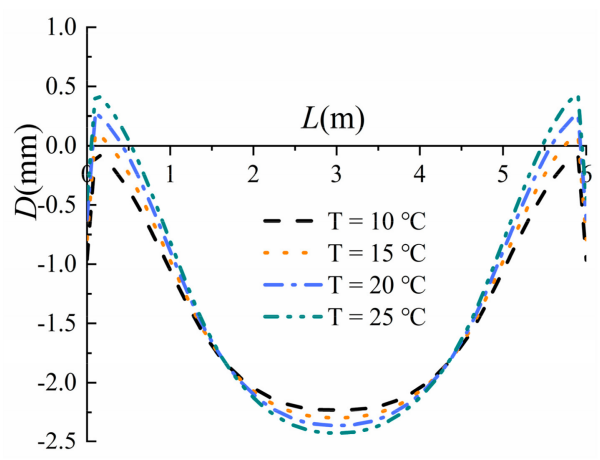

(c)

Figure 23. The displacement-temperature relationship of (a) the crown beam, (b) waist beam 1, and (c) waist beam 2 .

\section{Conclusions}

Through the full-scale test and numerical simulation of a steel assembled supporting structure, the impact of the temperature on the internal force on this type of supporting structure was explored, and the deformation process of the supporting structure under the temperature effect was evaluated. The following main conclusions can be drawn from the above results and discussion:

(1) Under the action of the thermal stress, the horizontal displacement of the retaining pile above the excavation face was more prominent. The deflection of waist beam 2 increased with the temperature rise, which made the deformation of retaining pile 3 consist of rigid rotation and flexural deformation, while retaining pile 2 only experienced flexural deformation.

(2) In the heating stage, the crown of all the retaining pile moved out of the pit, and the horizontal displacement of the retaining pile crowns was in good agreement with the trend of change in the temperature. Moreover the horizontal displacement of the middle retaining pile crown increased more rapidly with the temperature rise.

(3) Comparing our results with other works revealed that, at the same temperature difference, the horizontal displacement of steel support structures changes more significantly than that of concrete support structures. 
(4) After the excavation of the foundation pit was completed, the stress on the retaining pile near the excavation face was the largest; also, with the temperature rise, the stress on the retaining piles increased further. The increment in the stress on the bottom of the retaining piles was significantly greater than that in the stress on the crown of the retaining piles, which was extremely unfavorable to the stress on the piles. Therefore, the temperature effect should be considered as a working condition in design.

(5) As the temperature rose, the crown beam deformed outside the foundation pit, while the waist beams deformed in the opposite direction. Compared with the crown beam and waist beam 2 , the stress on waist beam 1 was more remarkably affected by the temperature; indeed, the stress on the end of waist beam 1 increased by $0.7 \mathrm{MPa} /{ }^{\circ} \mathrm{C}$, so the stress on this position should be paid enough attention.

(6) The rigid panels had a small stiffness, so they were severely affected by the temperature. For instance, when the temperature increased by $15^{\circ} \mathrm{C}$, the stress on rigid panels 1 and 2 enlarged by $78 \%$ and $82 \%$, respectively.

(7) The bending moment and shear strength of retaining pile 1 were markedly affected by the temperature, but piles 2 and 3 were basically stable. The deformation of the crown beam and the waist beams was coordinated with that of the retaining piles. After the temperature varied, the deflection of waist beam 2 changed the most, but the crown beam deflected the least.

(8) The internal forces on the retaining piles, the crown beam, and the waist beams were all within the allowable strength range of the materials, and the deformation satisfied the specification requirements. The numerical calculation data were similar to the full-scale test results, and their deformation trend was basically identical; therefore, the developed simulation can be used to calculate the impact of the temperature on supporting structures in such engineering projects.

Author Contributions: Conceptualization, C.Z.; Data curation, F.W., G.S. and B.L.; Formal analysis, W.Z.; Funding acquisition, H.F.; Investigation, C.Z. and H.F.; Methodology, F.W. and G.S.; Software, W.Z. and B.L.; Supervision, H.F.; Writing—original draft, F.W.; Writing—review \& editing, C.Z. All authors have read and agreed to the published version of the manuscript.

Funding: This research was funded by the National Key Research and Development Program of China (No. 2016YFC0802400); the National Natural Science Foundation of China (No. 51978630, 51909242, 52009125); the Scientific and Technological Research Program of Henan Province (No. 152102310066); the Outstanding Young Talent Research Fund of Zhengzhou University (1621323001); the Scientific Research Project of Science and Technology Innovation Fund of CCCC First Highway Consultants Co., Ltd.: Key Technology of Comprehensive Improvement of Water Environment in Urban Highly Built-up Area (KCJJ2018-10); the Science and Technology Fund Research Project of China Communications Construction Co., Ltd.: Research and Application Promotion of Key Technologies for Ecological Restoration of Water Environment (2019-ZJKJ-01); and the Program for Guangdong Introducing Innovative and Entrepreneurial Teams (HG-GCKY-01-002), for which the authors are most grateful.

Institutional Review Board Statement: Not applicable.

Informed Consent Statement: Not applicable.

Data Availability Statement: The data presented and discussed in this article are all available, and the readers can access the data supporting the conclusions of the study.

Acknowledgments: The authors would like to thank the anonymous reviewers for their constructive suggestions improving the quality of the paper.

Conflicts of Interest: The authors declare no conflict of interest.

\section{References}

1. Chen, X.Y.; Zhang, M.Y.; Bai, X.Y. Axial Resistance of Bored Piles Socketed into Soft Rock. KSCE J. Civ. Eng. 2019, $23,46-55$.

2. Xu, M.; Ni, P.; Ding, X.; Mei, G. Physical and numerical modelling of axially loaded bored piles with debris at the pile tip. Comput. Geotech. 2019, 114, 103146. 
3. Hu, Z.C.; Zhuang, K.W.; Hu, F.C. Application Researches on Lasson Steel Sheet Pile Based on Foundation Pit Support Close to Railway Bridge. Appl. Mech. Mater. 2011, 97-98, 414-417.

4. Wang, J.F.; Xiang, H.W.; Yan, J.G. Numerical Simulation of Steel Sheet Pile Support Structures in Foundation Pit Excavation. Int. J. Geomech. 2019, 19, 5019002.1-5019002.12.

5. Jiang, X.L.; Yang, H.; Wen, C.P.; Yin, J. Modeling for excavation procedure in soil nailed foundation pit. Electron. J. Geotech. Eng. 2013, 18, 1121-1130.

6. Moradi, M.; Babaki, A.P.; Sabermahani, M. Effect of Nail Arrangement on the Behavior of Convex Corner Soil-Nailed Walls. J. Geotech. Geoenvironmental Eng. 2020, 146, 04020026.

7. Cheng, F. STUDY on Quality Control of SMW Construction Pile in Foundation Pit Excavation of Soft Soil Foundation. IOP Conf. Ser. Earth Environ. Sci. 2017, 94, 012192.

8. Zhang, X.S.; Zhang, X.C.; Han, Y.S. A Case Study on Field Monitoring Analysis of Deep Foundation Pit in Soft Soils. Adv. Civ. Eng. 2019, 2019, 1-10.

9. Gao, X.H.; Tian, W.P.; Zhang, Z.P. Analysis of Deformation Characteristics of Foundation-Pit Excavation and Circular Wall. Sustainability 2020, 12, 3164.

10. Di, H.G.; Guo, H.J.; Zhou, S.H.; Chen, J.M.; Wen, L. Investigation of the Axial Force Compensation and Deformation Control Effect of Servo Steel Struts in a Deep Foundation Pit Excavation in Soft Clay. Adv. Civ. Eng. 2019, 2019, 1-16.

11. Yang, Y.Y.; Lv, J.G.; Huang, X.G.; Tu, X.M. Sensor monitoring of a newly designed foundation pit supporting structure. J. Cent. South Univ. 2013, 20, 1064-1070.

12. Cui, X.Y.; Ye, M.G.; Zhuang, Y. Performance of a foundation pit supported by bored piles and steel struts: A case study. Soils Found. 2018, 58, 1016-1027.

13. Han, L.; Sun, M.; Wang, H.; Wang, G.X. Engineering Application and In-situ Monitoring Analysis of Retaining Structures of New H-section Steel Support System in Foundation Pit. In Proceedings of the E3S Web of Conferences (ICAEER2018), Guilin, China, 15-18 May 2018; Volume 53, p. 03080.

14. Pan, Y.H.; Fang, H.Y.; Li, B.; Wang, F.M. Stability analysis and full-scale test of a new recyclable supporting structure for underground ecological granaries. Eng. Struct. 2019, 192, 205-219.

15. Boone, S.J.; Crawford, A.M. Braced Excavations: Temperature, Elastic Modulus, and Strut Loads. J. Geotech. Geoenviron. Eng. 2000, 126, 870-881.

16. Massoudi, N. Temperature Effect on Tieback Loads. In International Foundation Congress E Equipment Expo; ASCE: Orlando, FL, USA, 2009; pp. 49-56.

17. Hashash, Y.M.; Marulanda, C.; Kershaw, K.A. Temperature Correction and Strut Loads in Central Artery Excavations. J. Geotech. Geoenviron. Eng. 2003, 129, 495-505.

18. Chapman, K.P.; Cording, E.J.; Schnabel, H. Performance of a Braced Excavation in Granular and Cohesive Soils; ASCE: Purdue, IN, USA, 1996; Volume 93, pp. 432-442.

19. Yao, Z.L.; Bai, G.L.; Dang, F.N. Analysis on a Steel-Concrete Hybrid Structure Temperature Effect and Supporting Block Design. Appl. Mech. Mater. 2010, 29-32, 1862-1865.

20. Hu, Q.; Lin, D.S.; Cheng, Z.H.; Chen, Z. Effects of temperature stress on diaphragm wall of circular deep foundation pit. Chin. J. Geotech. Eng. 2013, 35, 2139-2143.

21. Wu, M.; Du, C.; Yang, K.; Geng, X.Y. A new empirical approach to estimate temperature effects on strut loads in braced excavation. Tunn. Undergr. Space Technol. 2019, 94, 103115.

22. Liu, C.; Zhang, Y.L.; Zheng, G.; Sun, P.P. Modified method for calculating temperature stress and displacement in horizontal strut of foundation pits. Chin. J. Geotech. Eng. 2015, 37, 61-64.

23. Li, G.P.; Xi, W.Z. Finite Element Analysis of the Influence of Deep Foundation Pit Excavation Construction on Adjacent Subway Tunnel Structure. In Proceedings of the IOP Conference Series: Materials Science and Engineering, Chongqing, China, 20-21 September 2020; Volume 741, p. 012098.

24. Yu, C. Numerical Analysis of Deep Foundation Pit Excavation under Complex Beam Support. IOP Conf. Ser. Earth Environ. Sci. 2019, 242, 062027.

25. Xu, H.F.; Wu, H.J.; Guo, S.P.; Liao, T.P. Study on the Parameters of Pile Soil Contact Surface Element. Explor. Eng. 2002, 29 , 10-12.

26. Mirzazadeh, M.M.; Green, M.F. Non-linear finite element analysis of reinforced concrete beams with temperature differentials. Eng. Struct. 2017, 152, 920-933. 